(2) Open Access Full Text Article

\title{
Sweating of Descemet's membrane during deep anterior lamellar keratoplasty in absence of perforation
}

This article was published in the following Dove Press journal:

Clinical Ophthalmology

4 September 2012

Number of times this article has been viewed

\author{
Karim Mohamed-Noriega ${ }^{1,2}$ \\ Jodhbir S Mehta ${ }^{1-4}$ \\ 'Tissue Engineering and Stem Cell \\ Group, Singapore Eye Research \\ Institute, ${ }^{2}$ Corneal and External \\ Disease Service, Singapore National \\ Eye Centre, ${ }^{3}$ Department of \\ Ophthalmology, Yong Loo Lin School \\ of Medicine, National University of \\ Singapore, ${ }^{4}$ Department of Clinical \\ Sciences, Duke-NUS Graduate \\ Medical School, Singapore
}

\begin{abstract}
We report a case of spontaneous Descemet's membrane sweating of aqueous humor during a manual deep anterior lamellar keratoplasty (DALK) without perforation of Descemet's membrane. An 81-year-old female developed a neurotrophic central ulcer with descemetocele in the right eye, and her visual acuity was count fingers at $30 \mathrm{~cm}$. She was unresponsive to medical treatment, and an uneventful manual DALK was performed. Six months after surgery, unaided visual acuity improved to 6/30. Seven months after surgery, the patient had a decrease in visual acuity to count fingers in the same eye. She was diagnosed as having corneal melting with a central descemetocele in the previous lamellar graft. A repeat manual DALK graft was performed. Lamellar dissection was performed starting from the edge of descemetocele, proceeding to the corneal periphery and maintaining the surgical plane of the previous DALK. During the surgical procedure, continuous and localized sweating of aqueous through Descemet's membrane was observed in the area of the descemetocele. After drying of the recipient bed, no visible perforation of Descemet's membrane was found. After removal of the previous DALK graft, a new stromal lamellar graft was sutured. The surgery was concluded without complications. One day after surgery, the graft was clear, with no detachment of Descemet's membrane. If Descemet's membrane sweating is observed during DALK and there is no visible perforation, the reason may be a hidden micron perforation in an intact Descemet's membrane. It is recommended to continue with surgery maintaining maximum diligence and low intraocular pressure to prevent extension of micron perforation.
\end{abstract}

Keywords: deep anterior lamellar keratoplasty, perforation, Descemet's membrane, sweating

\section{Introduction}

Deep anterior lamellar keratoplasty (DALK) is a selective corneal transplantation procedure indicated for corneal opacities limited to the stroma. ${ }^{1}$ The most common intraoperative complication is a perforation. ${ }^{1} \mathrm{~A}$ manual dissection technique using a combination of hydration and dehydration allows good visualization of the surgical plane and early identification of intraoperative perforation. ${ }^{1}$ Descemetocele, an end-stage complication of corneal ulcers, can be treated with DALK. ${ }^{1-3}$ Here we describe a case of manual DALK graft replacement with continuous and localized sweating of aqueous from Descemet's membrane without visible membrane perforation.

\section{Case report}

An 81-year-old Chinese female presented with an inflamed right eye and blurred vision of count fingers at $30 \mathrm{~cm}$. She had hyperemia, anterior chamber cells, central corneal edema, and corneal thinning. She had severe meibomian gland dysfunction 
with a poor ocular surface and 360 degree pannus. No microorganisms were isolated from corneal scrape cultures and staining. She was diagnosed as having a central corneal ulcer with underlying neurotrophic etiology. Despite one week of intensive medical treatment with fortified antibiotics, lubricants, and oral doxycycline, she progressed to develop a central descemetocele $(1.8 \times 1.5 \mathrm{~mm})$. A predescemetic manual DALK was successfully performed. The residual stromal bed was $50 \mu \mathrm{m}$, and no intraoperative Descemet's membrane perforation or postoperative complications occurred. Six months after surgery the graft was clear, the ocular surface was healed, and suture removal was completed. Unaided visual acuity was $6 / 30$ due to the presence of cataract.

One month later, she presented with blurred vision of count fingers at $30 \mathrm{~cm}$. She developed cornea melting with a central descemetocele $(1.2 \times 0.8 \mathrm{~mm})$ over the DALK graft which was located in the same area as the previous descemetocele (Figure 1A). She underwent repeat manual DALK. Dissection was performed starting from the edge of the descemetocele, proceeding to the corneal periphery while maintaining the plane of the previous DALK dissection with the aid of a blunt marginal dissector. Continuous accumulation of aqueous fluid was observed over the dissection plane. Constant drying of the cornea was necessary to proceed with the surgery (Figure 1B and C). Although a perforation was suspected, it was never observed. The dissected stromal graft was cut with Anwar scissors as in a standard DALK. ${ }^{1}$ Following complete removal of the lamellar graft, a localized area of Descemet's membrane sweating of aqueous was identified in an area of intact Descemet's membrane (Figure 1D-G). The anterior chamber remained formed throughout surgery, although digitally the eye felt soft. A new graft was sutured as in standard DALK ${ }^{1}$ (Figure $1 \mathrm{H}$ ). On the first postoperative day the graft was clear, well attached to the recipient stroma, and there was no evidence of detachment of Descemet's membrane.

\section{Discussion}

There is controversy about the possibility of aqueous sweating through an intact Descemet's membrane. ${ }^{4-7}$ There are a few published letters that have commented about leakage of aqueous through the center ${ }^{4}$ or the periphery ${ }^{5}$ of Descemet's membrane during uneventful DALK. However, these reports lack detailed documentation and photographic or video evidence. Many ophthalmologists would agree that there is no visible sweating of Descemet's membrane during DALK. To the best of our knowledge, this is the first detailed documented case of aqueous sweating from Descemet's membrane without any visible perforation during DALK (Figure 1).

In our case, sweating of Descemet's membrane was located exactly where both previous descemetoceles were located (Figure 1). Although a localized incompetent endothelial pump cannot be excluded, the most probable explanation was a small, optically undetected micron perforation in an intact

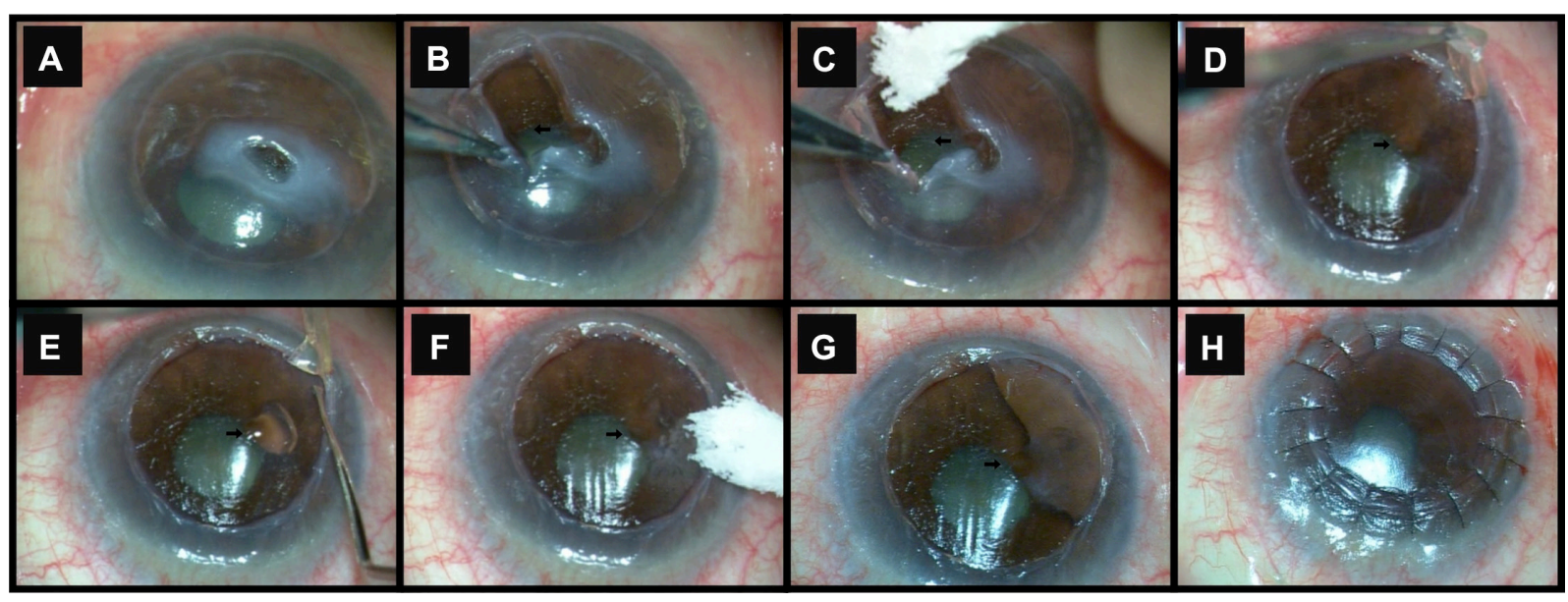

Figure I Consecutive images of a repeat manual deep anterior lamellar keratoplasty (DALK). During the procedure, there was continuous localized sweating of aqueous through Descemet's membrane, but no microperforation was observed. (A) Central descemetocele due to cornea melting in uncomplicated DALK 7 months after surgery for a suspected neurotrophic central ulcer with descemetocele. (B) Sweating of aqueous through Descemet's membrane and subsequent accumulation of fluid (arrow) over the recipient bed. The fluid prevents clear visualization of the surgical plane. (C) Recipient bed immediately after drying of the sweating. Now it is possible to see the surgical plane clearly and no microperforation is identified. (D and E) Consecutive images taken 15 seconds apart showing localized and continuous sweating through Descemet's membrane (arrows). (F and $\mathbf{G})$ Consecutive images after complete manual dissection. The former is immediately after drying of the recipient bed and the latter is after 2 minutes of continuous sweating of aqueous from Descemet's membrane. The arrows indicate the specific location of Descemet's membrane that sweats; perhaps an area with a nonvisible micron perforation. $(\mathbf{H})$ Final image after successful redo DALK. 
posterior nonbanded Descemet's membrane layer. The tear film of an inflamed eye has increased levels of cytokines and metalloproteinases (specifically matrix metalloproteinase-9) ${ }^{8}$ that could damage the exposed anterior banded Descemet's membrane, favoring localized sweating from this area. Low intraocular pressure may be the reason why it did not extend to a microperforation or a macroperforation.

In DALK surgery, the presence of fluid over the dissection plane requires the ophthalmologist to suspect a perforation. If sweating of Descemet's membrane is observed and there is no visible perforation, the reason may be a hidden micron perforation. Hence, in this scenario, it is recommended to proceed with surgery, maintaining maximum diligence and a low intraocular pressure to prevent extension of micron perforation.

\section{Disclosure}

The authors report no conflicts of interest in this work.

\section{References}

1. Luengo-Gimeno F, Tan DT, Mehta JS. Evolution of deep anterior lamellar keratoplasty (DALK). Ocul Surf. 2011;9(2):98-110.

2. Gabison EE, Doan S, Catanese M, Chastang P, Ben M'hamed M, Cochereau I. Modified deep anterior lamellar keratoplasty in the management of small and large epithelialized descemetoceles. Cornea. 2011;30(10):1179-1182.

3. Sharma N, Kumar C, Mannan R, Titiyal JS, Vajpayee RB. Surgical technique of deep anterior lamellar keratoplasty in descemetoceles. Cornea. 2010;29(12):1448-1451.

4. Unlu K, Akata F. Does central Descemet's membrane leak fluid. J Cataract Refract Surg. 2000;26(4):476-476.

5. Stegmann R, Pienaar A, Miller D. Viscocanalostomy for open-angle glaucoma in black African patients. J Cataract Refract Surg. 1999;25(3): 316-322.

6. Teichmann KD. How leaky is Descemet's membrane? J Cataract Refract Surg. 1999;25(10):1309.

7. Spiegel D, Schefthaler M, Kobuch K. Outflow facilities through Descemet's membrane in rabbits. Graefes Arch Clin Exp Ophthalmol. 2002;240(2):111-113.

8. Pflugfelder SC. Tear dysfunction and the cornea: LXVII Edward Jackson Memorial Lecture. Am J Ophthalmol. 2011;152(6):900. e1-909. e1.
Clinical Ophthalmology

\section{Publish your work in this journal}

Clinical Ophthalmology is an international, peer-reviewed journal covering all subspecialties within ophthalmology. Key topics include: Optometry; Visual science; Pharmacology and drug therapy in eye diseases; Basic Sciences; Primary and Secondary eye care; Patien Safety and Quality of Care Improvements. This journal is indexed on

Submit your manuscript here: http://www.dovepress.com/clinical-ophthalmology-journal

\section{Dovepress}

PubMed Central and CAS, and is the official journal of The Society of Clinical Ophthalmology (SCO). The manuscript management system is completely online and includes a very quick and fair peer-review system, which is all easy to use. Visit http://www.dovepress.com/ testimonials.php to read real quotes from published authors. 